\title{
Polyethylene glycol-conjugated growth hormone-releasing hormone is long acting and stimulates GH in healthy young and elderly subjects
}

\author{
A Munafo, T X Q Nguyen, O Papasouliotis, H Lécuelle, A Priestley ${ }^{1}$ and M O Thorner ${ }^{2}$ \\ Serono International S.A., 15 bis chemin des Mines, PO box 54, 1211 Genèva 20, Switzerland, ${ }^{1}$ Bourn Hall Clinic, Cambridge, UK and ${ }^{2}$ Department \\ of Medicine, University of Virginia, Charlottesville, Virginia, USA \\ (Correspondence should be addressed to A Munafo; Email: alain.munafo@serono.com)
}

\begin{abstract}
Objective: The clinical use of growth hormone-releasing hormone (GHRH) is limited by its short halflife. Polyethylene glycol-conjugated GHRH (PEG-GHRH) was developed to provide increased stability compared with the currently available GHRH(1-29). This study aimed to evaluate the safety, tolerability and pharmacodynamics of PEG-GHRH.

Design: PEG-GHRH was administered by subcutaneous injection to young healthy men $(n=12)$ and elderly men and women (aged $>60$ years; $n=20$ ).

Results: In both groups, administration of PEG-GHRH generated a clear increase in circulating GH compared with placebo. Following single-dose $(0.25,0.5,2$ or $4 \mathrm{mg})$ administration to young subjects, the effect persisted for $12 \mathrm{~h}$, but a sustained increase was observed on repeated administration to the elderly. Serum insulin-like growth factor-I also increased in response to PEG-GHRH treatment. Injection-site reactions were more frequent with PEG-GHRH compared with placebo, but these were mild and transient; other adverse events were similar to those observed after placebo. Some impairment of glucose tolerance was observed in the elderly following repeated administration of PEGGHRH. Antibodies to GHRH were not observed. Conclusions: PEG-GHRH offers the possibility of less frequent dosing compared with GHRH. This possibility deserves further clinical testing.
\end{abstract}

European Journal of Endocrinology 153 249-256

\section{Introduction}

Thorner and colleagues were intrigued by observations of two patients with ectopic growth hormone-releasing hormone (GHRH) secretion, arising either from a pancreatic islet tumour or from a metastatic carcinoid tumour, that gave rise to acromegaly $(1,2)$. Despite persistently elevated GHRH levels throughout a 24-h observation period, the pattern of growth hormone $(\mathrm{GH})$ release remained pulsatile. This suggested that factors other than GHRH, such as somatostatin, are likely to be involved in regulating the pulsatile pattern of GH secretion. Such ectopic GHRH secretion also suggests that use of a long-acting GHRH agonist could increase pulsatile GH secretion in the clinical setting. Indeed, increased pulsatile GH secretion has been observed in studies investigating continuous intravenous GHRH infusion in normal individuals, further indicating that depot or long-acting GHRH preparations may be clinically useful (3). GHRH is a 44amino acid peptide secreted by the hypothalamus that regulates the expression, synthesis and release of $\mathrm{GH}$ from the somatotroph cells of the anterior pituitary (4). A peptide consisting of the first 29 amino acids of human GHRH (hGHRH(1-29); sermorelin) retains the biological activity of the full-length peptide (5) and has been used clinically for the treatment of $\mathrm{GH}$ deficiency in children (6). More recently, the potential of GHRH to reverse the age-related decline in the function of the somatotrophic $\mathrm{GH}$-insulin-like growth factor (IGF)-I axis has been evaluated (7).

A pharmaceutical preparation of hGHRH(1-29) has been available for clinical use (Geref, Laboratoires Serono S.A., Aubonne, Switzerland). However, its pharmacological value is limited by its short half-life (approximately $12 \mathrm{~min}$ following intravenous injection in humans), mainly due to its susceptibility to rapid enzymatic degradation (8). There is thus a clinical need for a preparation of GHRH with a longer half-life for the potential treatment of GH deficiency and other indications for which GHRH is used.

Conjugation with polyethylene glycol (PEG; PEGylation) is a widely used approach for improving the stability of peptide and protein drugs $(9,10)$, and a number 
of PEGylated molecules are approved for clinical use. Therefore, we applied this technique with the objective of obtaining a more stable form with improved physicochemical and biological characteristics compared with the parent molecule. In particular, PEGylation was aimed at increasing stability to degradation by the protease dipeptidylpeptidase IV, potentially improving bioavailability and prolonging plasma half-life and hence increasing the pharmacodynamic response of the somatotrophic axis.

No bioanalytical method is available to date to specifically measure GHRH(1-29), GHRH or PEGGHRH, which differ from their primary inactive metabolite by only two amino acids. Consequently, the improved pharmacokinetic profile of PEG-GHRH was assessed by means of its impact on GH secretion.

The methods used to develop PEG-GHRH and the results of pre-clinical evaluation have been reported previously (11). Briefly, PEG-GHRH is a mono-PEGylated molecule consisting of an almost equimolar mixture of two isomers, conjugated at positions Lys ${ }^{12}$ and $\mathrm{Lys}^{21}$. PEG-GHRH has a higher solubility in water and aqueous buffers compared with GHRH. Due to the presence of the PEG chain, the product has a prolonged half-life in plasma (11). As a result, a single injection of PEG-GHRH generates, in animal models, a sustained pharmacodynamic response characterized by multiple GH peaks.

These characteristics should lead to a product requiring less frequent administrations than GHRH(1-29). Furthermore, the improved solubility of the molecule may contribute to improved local tolerability. The results of two placebo-controlled studies designed to evaluate the safety and pharmacodynamics of PEGGHRH in healthy young (single dose) and elderly (repeated dose) subjects are reported here.

\section{Study population and methods}

Both studies were conducted in accordance with the ethical principles set out in the Declaration of Helsinki and in the European Guidelines for Good Clinical Practice, and were approved by the Cambridge Local Research Ethics Committee (single-dose study) and the Huntingdon Local Research Ethics Committee (repeated-dose study). All subjects gave written informed consent before starting the study. For both studies, injections were administered at about $0900 \mathrm{~h}$ $( \pm 1 \mathrm{~h})$, and pre-dose assessments were made before the first dosing.

\section{Study design}

Single-dose study This was a phase I, double-blind, placebo- and GHRH-controlled study in healthy male subjects. Subjects were $18-50$ years old, weighed $\geq 60 \mathrm{~kg}$ and had a body mass index (BMI) $<28 \mathrm{~kg} / \mathrm{m}^{2}$. Exclusion criteria included smoking more than five cigarettes per day, any clinically significant disease, history of drug or alcohol abuse and any recent use of prescribed or overthe-counter medications.

Each subject received four subcutaneous injections: placebo, GHRH and two PEG-GHRH doses $(0.5 \mathrm{mg}$ and $4 \mathrm{mg}$ in group 1 , and $2 \mathrm{mg}$ and $0.25 \mathrm{mg}$ in group 2). For each of the four dosing periods, there was a 7day interval between injections. The study subjects were admitted to the unit on the morning of day 1 and remained there until $48 \mathrm{~h}$ after injection. The subjects returned to the unit as an 'out-patient' for the subsequent post-dose samples. Physical activity and diet were controlled from $48 \mathrm{~h}$ before injection until $24 \mathrm{~h}$ afterwards. Fluid intake was controlled and consistent from $1 \mathrm{~h}$ before dosing to $4 \mathrm{~h}$ following drug administration. The order of injections was determined using a centrally generated randomization scheme. Both study subjects and investigators were unaware of the assigned order of injections for each subject.

Repeated-dose study This was an open, randomized, placebo-controlled study in which every subject received placebo and either 2 or $4 \mathrm{mg}$ PEG-GHRH daily for 6 consecutive days in a crossover design. The sequence of treatments was determined at random, while allocation to the high- or low-dose PEG-GHRH group depended on order of enrolment. For both periods of treatment, the subjects attended the unit on the evening before the first administration and remained there until $24 \mathrm{~h}$ after the last dose. Physical activity and smoking were restricted while subjects were in the unit. Fluid intake was controlled from $1 \mathrm{~h}$ before each injection until $4 \mathrm{~h}$ afterwards. A wash-out period of 4-6 weeks separated the two study periods.

Subjects were men and women were $\geq 60$ years old, weighed $\geq 60 \mathrm{~kg}$ for males and $\geq 50 \mathrm{~kg}$ for females, with a BMI $\leq 30 \mathrm{~kg} / \mathrm{m}^{2}$ and with no clinically significant illness. The maximum BMI was slightly greater than in the single-dose study, as subjects were older and females were included. All subjects had an oral glucose tolerance test (OGTT) as part of the pre-study screening process.

Twenty subjects were studied to allow a placebo-controlled assessment of tolerability and pharmacodynamics, with each subject serving as his/her own control.

\section{Safety and tolerability}

Safety and tolerability endpoints were: clinical examination, laboratory safety tests, vital signs, electrocardiogram (ECG) parameters, adverse events (AEs) and injection-site reactions. In the repeated-dose study, clinical laboratory analysis (haematology and blood chemistry, including triglycerides) was performed at the pre- and post-study examination as well as predose on days 1, 2, 4 and 6 . Total thyroxine $\left(\mathrm{T}_{4}\right)$ and 
free thyroxine (free $\mathrm{T}_{4}$ ) were measured at screening, before dosing on days 5 and 6 of each treatment period, and at follow-up. Analysis for fasting glucose and insulin was performed at the post-study examination as well as pre-dose on days 1, 2, 4 and 6. An OGTT was performed on day 6 of each period according to the World Health Organization guidelines (12). Blood samples were taken before and at $30 \mathrm{~min}, 1 \mathrm{~h}$ and $2 \mathrm{~h}$ after ingestion of glucose. The OGTT was repeated after the end of the study if found to be abnormal at the last treatment dose.

\section{Pharmacodynamics}

GH profiles Blood samples were collected before dosing and then every $20 \mathrm{~min}$ up to $24 \mathrm{~h}$ post-dose in the single-dose study, and every $30 \mathrm{~min}$ up to $12 \mathrm{~h}$ postdose in the repeated-dose study. Serum GH was measured using a single antibody radioimmunoassay (Daiichi Pharmaceutical Co., Ltd, Tokyo, Japan) with a standard range of $0.1-50 \mathrm{ng} / \mathrm{ml}$ and intra- and interassay coefficients of variation of $0.8-1.3 \%$ and $1.4-2.1 \%$ respectively. The integrated area under the effect vs time curve (AUE) was calculated for different time intervals as follows: $\mathrm{AUE}_{0-6}, \mathrm{AUE}_{\mathrm{O}-12}, \mathrm{AUE}_{0-24}$, $\mathrm{AUE}_{6-12}$ and $\mathrm{AUE}_{12-24}$. Only $\mathrm{AUE}_{0-6}, \mathrm{AUE}_{0-12}$ and $\mathrm{AUE}_{6-12}$ were determined in the repeated-dose study. Other measures of treatment effect on GH concentrations were number of peaks, maximum peak attained (Cmax) and average valley (tone). These were estimated based on serum GH concentrations using a 'pseudo cluster analysis' (13).

IGF-I serum concentration was determined during each period pre-dose, and every $24 \mathrm{~h}$ up to $72 \mathrm{~h}$ post-dose in the single-dose study, or up to $168 \mathrm{~h}$ after the last dose in the repeated-dose study. AUE and Cmax were calculated. IGF-I was dissociated from IGF-binding proteins (IGFBP) using an acidic buffer and the sample IGF-I was measured by a double antibody radioimmunoassay, involving competitive binding of sample IGF-I with ${ }^{125}$ Ilabelled IGF-I (Mediagnost GmbH, Tubingen, Germany). The standard range of this assay was $15.6-1,000 \mathrm{ng} / \mathrm{ml}$, with intra- and interassay coefficients of variation of 3.2 and $7.4 \%$ respectively.

In the repeated-dose study, IGFBP-3 was measured by means of a radioimmunoassay using a specific, high-affinity polyclonal antibody that quantitatively recognizes the complete IGFBP-3 and is unaffected by excesses of IGF-I or IGF-II (Mediagnost, Reutlingen, Germany) with a standard range of $0.625-40 \mathrm{ng} / \mathrm{ml}$ and intra- and interassay coefficients of variation of $7-18.8 \%$ and $1.5-7.2 \%$ respectively. For serum IGFBP-3 measurement, blood samples were taken during each period at the following time points: predose on days $1,2,4$ and 6 , then at $6,12,24,48$, 96,120 , and $168 \mathrm{~h}$ after the dose on day 6 . AUE and Cmax were calculated.

\section{Statistics}

In the single-dose study, following log transformation, descriptive statistics were computed for the pharmacodynamic parameters, followed by analysis of variance (ANOVA) as appropriate. Selected pairwise comparisons were performed. For parameters relating to IGF-I, following log transformation, an analysis of covariance (ANCOVA) was performed with baseline IGF-I as a covariate. The OGGT results for the three dose groups were compared by ANOVA, and the baseline (pre-study) values were used as a covariate.

In the repeated-dose study, both parameters relating to $\mathrm{GH}$ concentration and those relating to IGF-I and IGFBP-3 concentrations were log-transformed and subjected to linear mixed effects models analysis. If the factor treatment or any of its interactions were found to be significant, relevant pairwise comparisons were performed.

Statistical analysis was performed using SAS Version 8.02 (SAS institute Inc., Cary, NC, USA).

\section{Results}

\section{Study population}

Twelve healthy male subjects were recruited to the single-dose study, six in each group; one of the originally recruited subjects withdrew consent after the first injection and was replaced. The subjects ranged from 19 to 44 years old, and had a mean ( \pm s.D.) age of 28.6 \pm 8.5 years and a mean BMI of $24.15 \pm 2.5 \mathrm{~kg} / \mathrm{m}^{2}$; ten were Caucasian, two were Black, and one was Arabic (including the subject who withdrew); five were light smokers. Six subjects were assigned to group 1 (0.5 and $4 \mathrm{mg}$ injections of PEGGHRH) and six to group 2 (2 mg and $0.25 \mathrm{mg}$ PEGGHRH injections).

Twenty subjects (10 men and 10 women) were included in the repeated-dose study, divided into two groups of 10 (five men and five women) for the low ( $2 \mathrm{mg})$ and high (4 mg) PEG-GHRH dose groups respectively. The subjects ranged from 61 to 77 years old, and had a mean ( \pm s.D.) age of $66.4 \pm 4.6$ years and a mean BMI of $26.1 \pm 2.5 \mathrm{~kg} / \mathrm{m}^{2}$. All were Caucasian and all except one were nonsmokers. All subjects who enrolled completed the study.

\section{Safety and tolerability}

Following a single dose of PEG-GHRH, no serious AEs were observed; results of physical examination findings, vital signs, 12-lead ECG recordings and safety laboratory parameters were within the normal range in these healthy men. None of the subjects developed anti-PEG-GHRH antibodies. A total of 34 AEs were recorded; 10 AEs were experienced by subjects when administered PEG-GHRH, 13 with GHRH and 11 by 
subjects administered placebo. Thirty of the AEs were of mild severity. Of the 27 AEs considered to be possibly or probably related to treatment, all but one were of mild intensity. The tolerability of PEG-GHRH appeared to be similar to that of GHRH in terms of investigatorassessed injection-site redness and swelling. Injectionsite reactions classed as AEs were reported after injection of GHRH but there were no injection-site reactions classed as AEs after PEG-GHRH injection. The most prevalent AEs (all AEs occurring more than once) are presented in Table 1.

Eighteen subjects reported a total of 102 AEs during the repeated-dose study. The majority of AEs that were considered possibly treatment-related occurred during treatment with placebo, while AEs considered probably treatment-related were all injection-site reactions. The majority of AEs were mild in each group (91 AEs; $89 \%$ ) and none was considered medically significant. Injection-site reactions (redness, swelling and itching) in subjects administered PEG-GHRH were transient and not thought to be clinically significant. The most common treatment-emergent AEs were headache (most common in the placebo group), injection-site paraesthesia and fatigue (Table 2).

Measurements of serum insulin revealed a tendency to increasing levels following repeated administration of PEG-GHRH, compared with placebo (data not shown). The increase was statistically significant for both doses $(P=0.0038$ for $2 \mathrm{mg}$ and $P=0.05$ for $4 \mathrm{mg}$ ). There was no statistically significant difference between the dose groups. Despite this increase, insulin remained within the normal range for the majority of subjects. Only one high result was recorded, a level of $228 \mathrm{pmol} / \mathrm{l}$ in one volunteer prior to the fourth PEGGHRH injection.

The OGTT results revealed an impairment of glucose tolerance in four subjects in each of the PEG-GHRH treatment groups, as compared with placebo. Mean glucose time course profiles are shown in Fig. 1. ANOVA demonstrated a statistically and clinically significant effect of treatment on AUE for both doses $(P=0.0053$ for $2 \mathrm{mg}$ and $P=0.0301$ for $4 \mathrm{mg})$. The observed glucose intolerances occurred predominantly (six of eight cases) in the first study period. Four subjects showed persistence of glucose intolerance into the second study period, such that the OGTT was also abnormal following placebo administration. One subject in the $4 \mathrm{mg}$ group developed an abnormal glucose tolerance, with sustained glucose levels above the normal range for more than $3 \mathrm{~h}$. His OGTT remained abnormal until several days after the last PEG-GHRH dose.

\section{Pharmacodynamics}

Single-dose study Serum GH concentrations following a single PEG-GHRH injection showed high inter-individual variability. Median GH serum concentration vs time profiles for the different dose groups are presented in Fig. 2. As expected, subjects treated with placebo had no clear GH peaks from 0 to $12 \mathrm{~h}$ post-dose (corresponding to the daylight hours) but produced clear nocturnal peaks. Following injection of GHRH or PEG-GHRH, most subjects showed a clear GH response (one or several peaks) during the first $6 \mathrm{~h}$ after GHRH and, following PEG-GHRH, several peaks of varying intensity were observed until $12 \mathrm{~h}$ postdose; the subjects also retained their physiological peaks during the night.

For the AUE measures, there was considerable overlap between the placebo responses and those on active treatment. Statistical analysis revealed a clear treatment effect on the primary response parameters $\mathrm{AUE}_{\mathrm{O}-6}, \mathrm{AUE}_{\mathrm{O}-12}, \mathrm{AUE}_{\mathrm{O}-24}$ and $\mathrm{AUE}_{6-12}$ but not on $\mathrm{AUE}_{12-24}$. $\mathrm{AUE}_{\mathrm{O}-6}$ was used to construct a $\mathrm{GH}$ doseresponse curve. The resulting curve (Fig. 3) could be described by a 'simple Emax model' with a baseline/placebo effect (E0). The maximum GH effect was approached for a dose of $1 \mathrm{mg}$ PEG-GHRH. The best estimate of the PEG-GHRH dose necessary to obtain $50 \%$ of the maximum effect $\left(\mathrm{ED}_{50}\right)$ was about $0.26 \mathrm{mg}$. GHRH and PEG-GHRH produced a statistically higher $\mathrm{GH}$ response than placebo. Globally, there was a trend towards a higher GH response to PEGGHRH at $2 \mathrm{mg}$ and $4 \mathrm{mg}$ compared with GHRH (for $\mathrm{AUE}_{0-12}, \mathrm{AUE}_{\mathrm{O}-24}$ and $\left.\mathrm{AUE}_{6-12}\right)$. However, not all pairwise comparisons were statistically significant and this finding needs to be interpreted with caution because of the high inter- and intra-subject variability in $\mathrm{GH}$ response following all treatments. Measurement

Table 1 Most prevalent adverse events (AEs) following a single injection of GHRH, PEG-GHRH or placebo in healthy male subjects.

\begin{tabular}{|c|c|c|c|c|c|c|c|}
\hline \multirow{2}{*}{$\begin{array}{l}\text { AEs } \\
\text { Adverse events }\end{array}$} & \multirow[b]{2}{*}{ GHRH } & \multicolumn{4}{|c|}{ PEG-GHRH } & \multirow[b]{2}{*}{ Placebo } & \multirow[b]{2}{*}{ Total no. of AEs } \\
\hline & & $0.25 \mathrm{mg}$ & $0.5 \mathrm{mg}$ & $2 \mathrm{mg}$ & $4 \mathrm{mg}$ & & \\
\hline Injection-site pain & 4 & 0 & 0 & 0 & 0 & 0 & 4 \\
\hline Back pain & 1 & 1 & 0 & 0 & 0 & 1 & 3 \\
\hline Headache & 1 & 0 & 0 & 1 & 0 & 1 & 3 \\
\hline Nausea & 1 & 1 & 0 & 0 & 0 & 1 & 3 \\
\hline Indigestion & 0 & 0 & 1 & 0 & 0 & 1 & 2 \\
\hline Venipuncture-site bruise & 1 & 0 & 0 & 0 & 0 & 1 & 2 \\
\hline
\end{tabular}


Table 2 Most prevalent treatment-emergent adverse events following repeated injections of PEG-GHRH or placebo in healthy elderly volunteers.

\begin{tabular}{|c|c|c|c|c|c|c|c|c|}
\hline \multirow[b]{2}{*}{ Preferred term } & \multicolumn{2}{|c|}{ PEG-GHRH (2 mg) } & \multicolumn{2}{|c|}{ PEG-GHRH (4 mg) } & \multicolumn{2}{|c|}{ Placebo } & \multirow[b]{2}{*}{$\begin{array}{l}\text { Total no. } \\
\text { of events }\end{array}$} & \multirow[b]{2}{*}{$\begin{array}{l}\text { Total no. } \\
\text { of subjects }\end{array}$} \\
\hline & $\begin{array}{l}\text { No. of } \\
\text { events }\end{array}$ & $\begin{array}{c}\text { No. of } \\
\text { subjects }\end{array}$ & $\begin{array}{l}\text { No. of } \\
\text { events }\end{array}$ & $\begin{array}{c}\text { No. of } \\
\text { subjects }\end{array}$ & $\begin{array}{l}\text { No. of } \\
\text { events }\end{array}$ & $\begin{array}{c}\text { No. of } \\
\text { subjects }\end{array}$ & & \\
\hline Palpitations & 1 & 1 & 1 & 1 & 3 & 3 & 5 & 5 \\
\hline Visual disturbance & 0 & 0 & 1 & 1 & 1 & 1 & 2 & 2 \\
\hline Diarrhoca & 1 & 1 & 1 & 1 & 0 & 0 & 2 & 2 \\
\hline Abdominal pain & 0 & 0 & 1 & 1 & 2 & 1 & 3 & 2 \\
\hline Nausea & 2 & 2 & 2 & 2 & 2 & 2 & 6 & 6 \\
\hline Injection-site pain & 1 & 1 & 1 & 1 & 0 & 0 & 2 & 2 \\
\hline Fatigue & 5 & 5 & 2 & 1 & 2 & 2 & 9 & $\overline{7}$ \\
\hline Injection site paraesthesia & 9 & 4 & 1 & 1 & 0 & 0 & 10 & 5 \\
\hline Venipuncture-site swelling & 1 & 1 & 1 & 1 & 0 & 0 & 2 & 2 \\
\hline Venipuncture-site bruise & 0 & 0 & 2 & 2 & 3 & 3 & 5 & 4 \\
\hline Back pain & 0 & 0 & 2 & 2 & 0 & 0 & 2 & 2 \\
\hline Myalgia & 0 & 0 & 1 & 1 & 2 & 1 & 3 & 2 \\
\hline Arthralgia & 1 & 1 & 1 & 1 & 2 & 2 & 4 & 2 \\
\hline Dizziness (excluding vertigo) & 3 & 3 & 0 & 0 & 4 & 3 & 7 & 4 \\
\hline Headache & 3 & 3 & 4 & 3 & 8 & 6 & 15 & 11 \\
\hline Epistaxis & 1 & 1 & 1 & 1 & 0 & 0 & 2 & 2 \\
\hline Injection-site rash & 1 & 1 & 0 & 0 & 1 & 1 & 2 & 2 \\
\hline Pruritus & 0 & 0 & 1 & 1 & 1 & 1 & 2 & 2 \\
\hline Rash & 0 & 0 & 0 & 0 & 2 & 1 & 2 & 1 \\
\hline
\end{tabular}

of the number of $\mathrm{GH}$ peaks, maximum $\mathrm{GH}$ concentration and $\mathrm{GH}$ tone did not provide additional knowledge on the pharmacodynamic response.

Baseline IGF-I concentration was about $160-210 \mathrm{ng} / \mathrm{ml}$ and differed substantially among the treatment groups. All groups (active treatment and placebo) showed some increase in serum IGF-I $24 \mathrm{~h}$ after injection. ANOVA revealed a significant treatment effect on Cmax and $\mathrm{AUE}_{0-72}$. However, as there was a

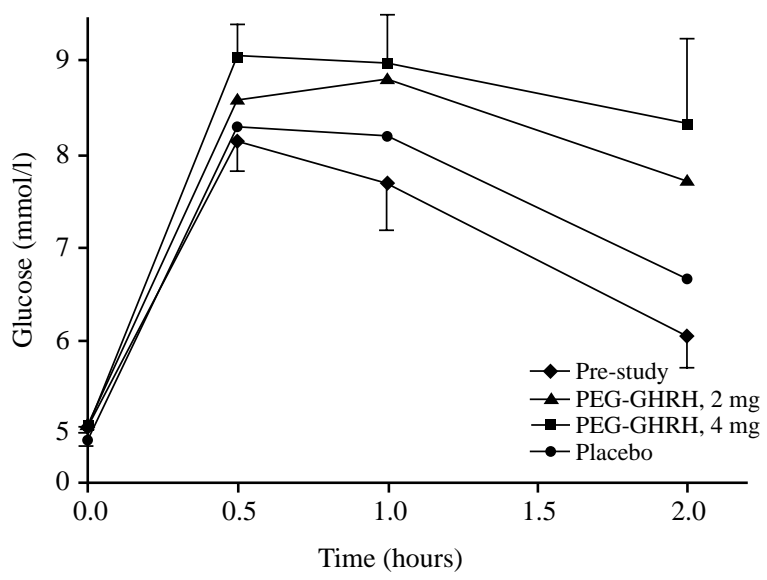

Figure 1 Oral glucose tolerance test results (repeated-dose study). Mean glucose time-course profile per treatment/study period is shown. Error bars represent the standard error of the mean. To aid visual clarity, only the upper error bars for the highest dose curve points, and the lower error bars for the baseline curve points are shown. Tests were conducted at screening to establish a baseline for the subject and immediately after the final drug administration in each study period $(n=20$ for pre-study and placebo; $n=10$ for PEG-GHRH, $2 \mathrm{mg}$ and $4 \mathrm{mg}$ ). significant period effect and a highly significant treatment-by-period interaction further interpretation of the treatment effect was not possible.

Repeated-dose study in elderly subjects There was a pronounced effect on GH secretion following PEGGHRH treatment in the repeated-dose study. Figure 4 shows the median response following injection of PEG-GHRH at $2 \mathrm{mg}$ and $4 \mathrm{mg}$ and after placebo. Interestingly, the response on day 6 appeared more pronounced than that following the first PEG-GHRH dose.

A statistically significant effect of PEG-GHRH on AUE was found for all time intervals over which AUE was computed (Table 3). Both PEG-GHRH doses gave a significantly higher AUE compared with placebo.

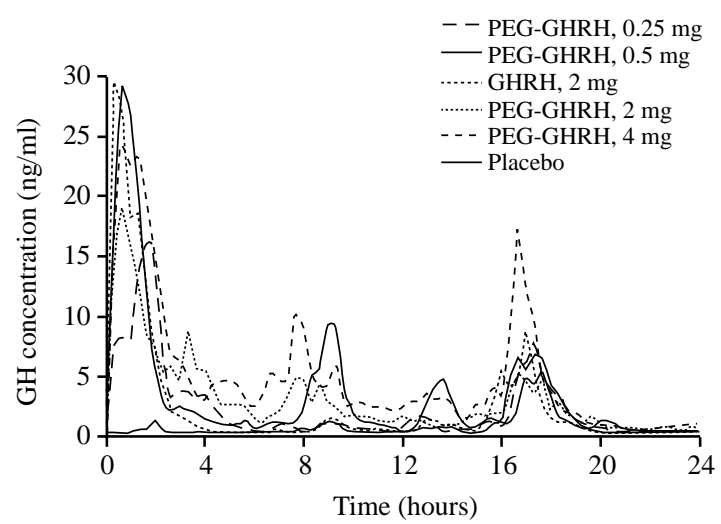

Figure 2 Median GH serum concentration time-course following single subcutaneous administration of PEG-GHRH, GHRH or placebo $(n=6$ or 12$)$. 


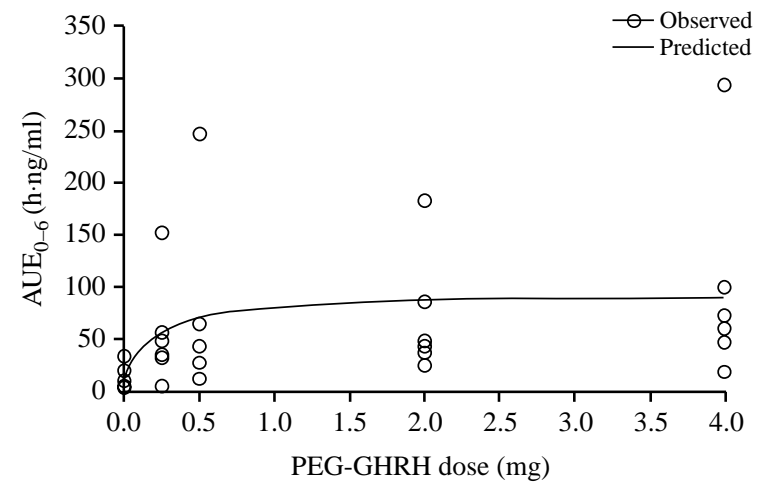

Figure 3 Dose-response curve (AUE, area under the effect vs time curve) for PEG-GHRH in healthy male subjects (single-dose study).

A significant gender effect and a gender-by-treatment interaction were found for $\mathrm{AUE}_{0-12}$ and $\mathrm{AUE}_{6-12}$ (Table 3). The GH response to PEG-GHRH was statistically higher in women than in men following the administration of $2 \mathrm{mg}$ PEG-GHRH. A significant day effect was found for $\mathrm{AUE}_{0-12}$ and $\mathrm{AUE}_{0-6}$, both of which were higher on day 6 than on day 1 .

Serum IGF-I remained constant following placebo administration and increased following repeated PEGGHRH administration (Fig. 5A). Values remained
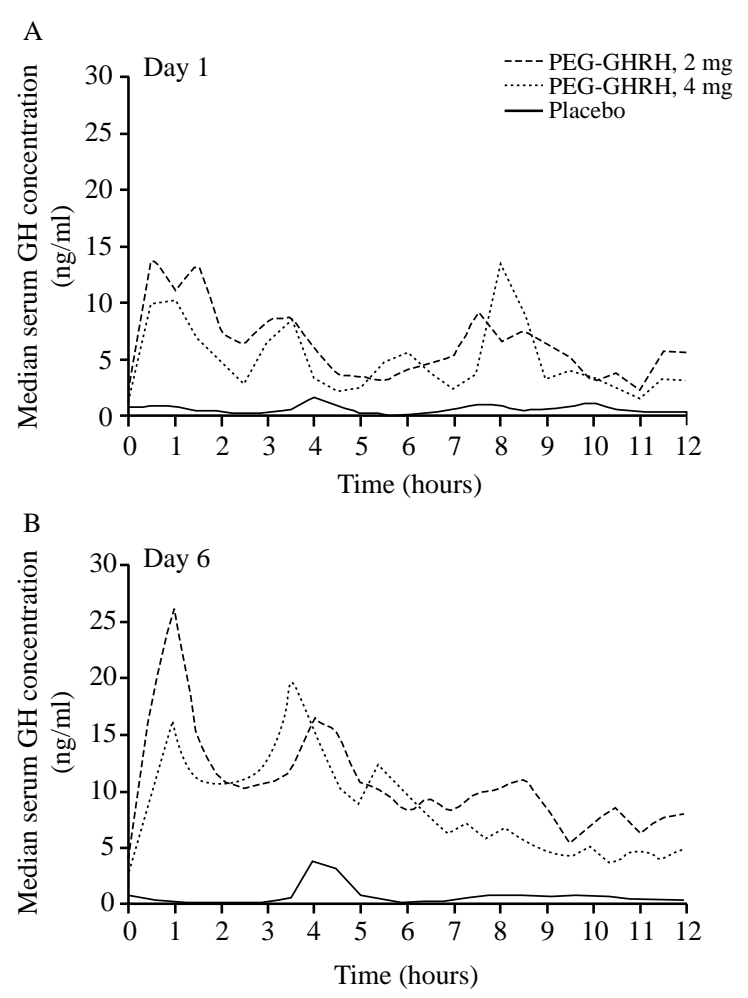

Figure 4 Median GH serum concentration time-course following repeated subcutaneous administration of PEG-GHRH, $2 \mathrm{mg}$ or $4 \mathrm{mg}$, or placebo, during the first (A) and last (B) treatment day. above pre-treatment levels for approximately 7 days after cessation of treatment. Statistical analysis taking the baseline level of IGF-I as a covariate revealed a significant effect of treatment on IGF-I concentration before the sixth PEG-GHRH dose, maximum concentration reached and integrated AUE over 1 week (all $P<0.0001)$. Gender effect and gender-by-treatment interaction reached significance for the two concentration parameters (women showing a stronger response than men), but not for the integrated AUE. Although serum IGF-I in all subjects responded more strongly to PEG-GHRH than to placebo, a large variability in response was observed. There was no significant correlation between an individual's GH and the IGF-I responses to PEG-GHRH.

Parallel to the changes in serum IGF-I levels, IGFBP-3 also increased following repeated PEG-GHRH treatment and serum concentrations remained above pre-treatment values for about 1 week after the last PEG-GHRH dose (Fig. 5B). Statistical analysis revealed a significant treatment effect for concentration before the sixth PEGGHRH dose, the maximum concentration reached and the integrated AUE for 1 week after the sixth dose $\left(\mathrm{AUE}_{0-168} ;\right.$ all $\left.P<0.0001\right)$. A period effect was detected
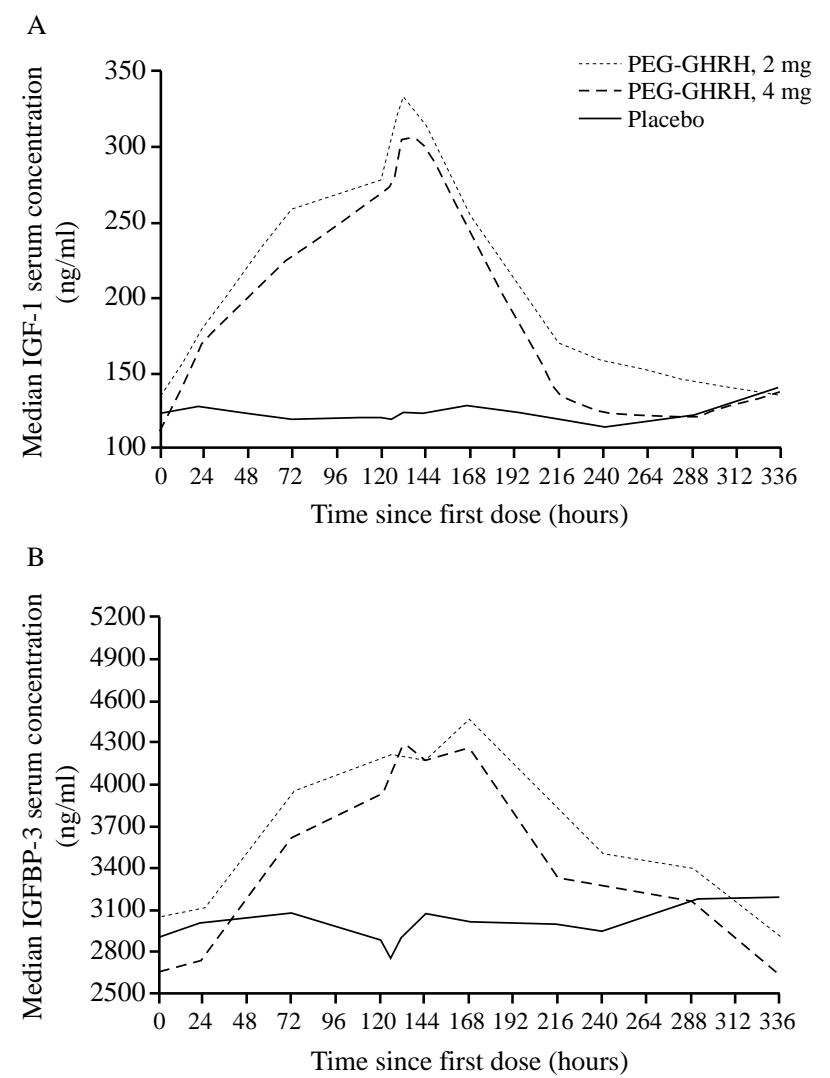

Figure 5 Median serum concentration time-courses for (A) IGF-I and (B) IGFBP-3 following six daily injections of PEG-GHRH, $2 \mathrm{mg}$ or $4 \mathrm{mg}$, or placebo. 
Table 3 Summary of statistical results on factors affecting growth hormone response in healthy elderly subjects administered PEGGHRH $2 \mathrm{mg}$ or $4 \mathrm{mg}$, or placebo.

\begin{tabular}{|c|c|c|c|c|c|c|}
\hline Parameter & Treatment & Period & Sex & Sex by treatment & Day & Day by treatment \\
\hline & $\begin{array}{c}P<0.0001 \\
4 \mathrm{mg}=2 \mathrm{mg}>\text { placebo }\end{array}$ & ns & $\begin{array}{c}P=0.038 \\
\text { Female }>\text { male at } 2 \mathrm{mg}\end{array}$ & $P=0.033$ & $\begin{array}{l}P=0.007 \\
\text { Day } 6>\text { day } 1\end{array}$ & ns \\
\hline & $\begin{array}{c}P<0.0001 \\
4 \mathrm{mg}=2 \mathrm{mg}>\text { placebo }\end{array}$ & ns & ns & ns & $\begin{array}{c}P=0.011 \\
\text { Day } 6>\text { day } 1\end{array}$ & ns \\
\hline $\mathrm{AUE}_{6-12}$ & $\begin{array}{c}P<0.0001 \\
4 \mathrm{mg}=2 \mathrm{mg}>\text { placebo (female) } \\
4 \mathrm{mg}>2 \mathrm{mg}>\text { Placebo (male) }\end{array}$ & ns & $\begin{array}{c}P=0.008 \\
\text { Female }>\text { male at } 2 \mathrm{mg}\end{array}$ & $P=0.011$ & ns & ns \\
\hline
\end{tabular}

AUE, area under the effect vs time curve; ns, not significant.

for Cmax and $\mathrm{AUE}_{0-168}$, values in treatment period 2 of the crossover design being higher than those in period 1.

For all markers (serum GH, IGF-I and IGFBP-3), women presented greater responses to PEG-GHRH than did men for some or all measures of response. In many cases, the difference between females and males reached statistical significance. This difference was only partly explained by differences in body weight.

\section{Discussion}

The results of these two studies demonstrate that administration of PEG-GHRH generated a clear increase in circulating $\mathrm{GH}$ levels in both healthy young and healthy elderly subjects. There was, however, significant inter- and intra-individual variation in response. The response appeared to plateau at higher doses, with no clear difference between the $2 \mathrm{mg}$ and $4 \mathrm{mg}$ doses. The dose-response curve calculated from the results of the single-dose study (Fig. 3) also suggests a peak GH response to PEG-GHRH at doses of $2 \mathrm{mg}$ or less. Following administration of a single dose to young male subjects, the response did not appear to last longer than about $12 \mathrm{~h}$, but a sustained increase in total secretion of $\mathrm{GH}$ and in its basal level was observed on repeated administration to elderly subjects. This suggests not only a persistence of the PEG-GHRH effect beyond the 24-h dosing interval but also the absence of development of tolerance to this effect over the duration of this study. The findings of the repeated-dose study indicate a lasting capacity of the (possibly re-sensitized) pituitary to respond to GHRH stimulation.

The effect of PEG-GHRH on the GH system is further supported by the sustained elevations observed in serum concentrations of both IGF-I and IGFBP-3. The levels of these mediators obtained after 6 days of PEGGHRH administration in the elderly approached or even exceeded the mean levels observed (albeit using different analytical methods) in younger healthy subjects (14). IGF-I levels continued to increase and did not reach a steady state in the repeated-dose study. In view of the dose-response curve obtained in the single-dose study, suggesting a maximum GH response to PEG-GHRH at doses below $2 \mathrm{mg}$, and the high IGF-I response to repeated administration in the elderly, future studies have the potential to investigate alternative dosing intervals to allow long-term administration of PEG-GHRH without the development of supraphysiologic levels of IGF-I. It would also be of interest to investigate the possibility that increasing serum IGF-I levels attenuate the effect of increasing the dose of PEGGHRH through a negative feedback mechanism.

A gender difference in response to PEG-GHRH seems possible, as female elderly subjects tended to respond more strongly than males and this difference was only partly explained by differences in body weight. Sex differences in GH response to GHRH have been reported previously but the results in the literature are contradictory, some authors reporting a higher response in women (15) and others in men (16-18). Further research is required to clarify this question and to separate the effect of sex differences from differences in body weight, age and route of administration.

PEG-GHRH was well tolerated, with no medically significant AEs possibly related to treatment in either study. Neither the frequency nor the severity of AEs appeared to be different from those following placebo, and there was no difference between the two doses on repeated administration. As expected, injection-site reactions, including redness and irritation, were more marked following injection of PEG-GHRH than after placebo injections. However, these reactions were transient and the local tolerability of PEG-GHRH was considered acceptable.

An impairment of glucose tolerance was observed in the elderly following repeated administration of PEGGHRH. This was quite pronounced in one subject in the $4 \mathrm{mg}$ dose group, who also showed elevated insulin levels. His OGTT remained abnormal for several days after the last treatment dose. Some effect of PEG-GHRH administration was also seen for triglycerides and free $\mathrm{T}_{4}$ levels. These are not unexpected findings and reflect the metabolic effects of GH. Previous studies with GH have shown that impaired glucose tolerance early in treatment may return to normal under continued therapy (without treatment interruption) $(14,19)$. 
A longer duration study would be required to confirm whether such a time course would occur also with PEG-GHRH.

Our results demonstrate that within the limitations of this small study, PEG-GHRH elicits a robust GH response, paralleled by increases in IGF-I and IGFBP-3, which, in turn, leads to metabolic effects. The balance between desired and untoward metabolic effects may be related to the dose and frequency of administration. The timecourse of the response, as well as the serum level of $\mathrm{GH}$ and IGF-I obtained after only six subcutaneous injections, suggests that PEG-GHRH offers the possibility of less frequent dosing compared with GHRH. This possibility deserves further clinical testing.

\section{References}

1 Thorner MO, Perryman RL, Cronin MJ, Rogol AD, Draznin M, Johanson A, Vale W, Horvath E \& Kovacs K. Somatotroph hyperplasia. Successful treatment of acromegaly by removal of a pancreatic islet tumor secreting a growth hormone-releasing factor. Journal of Clinical Investigation 198270 965-977.

2 Vance ML, Kaiser DL, Evans WS, Furlanetto R, Vale W, Rivier J \& Thorner MO. Pulsatile growth hormone secretion in normal man during a continuous 24-hour infusion of human growth hormone releasing factor (1-40). Evidence for intermittent somatostatin secretion. Journal of Clinical Investigation $1985 \mathbf{7 5}$ $1584-1590$

3 Thorner MO. The discovery of growth hormone-releasing hormone. Journal of Clinical Endocrinology and Metabolism $1999 \mathbf{8 4}$ $4671-4676$

4 Frohman LA \& Jansson JO. Growth hormone releasing hormone. Endocrine Reviews $19867223-253$.

5 Lance VA, Murphy WA, Sueiras-Diaz J \& Coy DH. Super-active analogs of growth hormone-releasing factor(1-29)-amide. Biochemical and Biophysical Research Communications 1984119 $265-272$.

6 Thorner M, Rochiccioli P, Colle M, Lanes R, Grunt J, Galazka A, Landy $\mathrm{H}$, Eengrand $\mathrm{P}$ \& Shah S. Once daily subcutaneous growth hormone-releasing hormone therapy accelerates growth in growth hormone-deficient children during the first year of therapy. Geref International Study Group. Journal of Clinical Endocrinology and Metabolism 199681 1189-1196.

7 Khorram O. Use of growth hormone and growth hormone secretagogues in aging: help or harm. Clinical Obstetrics and Gynecology $2001 \mathbf{4 4} 893-901$.

8 Frohman LA, Downs TR, Williams TC, Heimer EP, Pan YC \& Felix AM. Rapid enzymatic degradation of growth hormone-releasing hormone by plasma in vitro and in vivo to a biologically inactive product cleaved at the $\mathrm{NH}_{2}$ terminus. Journal of Clinical Investigation 198678 906-913.

9 Veronese FM. Peptide and protein PEGylation: a review of problems and solutions. Biomaterials 200122 405-417.

10 Harris JM, Martin NE \& Modi M. PEGylation: a novel process for modifying pharmacokinetics. Clinical Pharmacokinetics 200140 $539-551$.

11 Esposito P, Barbero L, Caccia P, Caliceti P, D'Antonio M, Piquet G \& Veronese FM. PEGylation of growth hormone-releasing hormone (GRF) analogues. Advanced Drug Delivery Reviews 200355 1279-1291.

12 World Health Organisation. Definition, diagnosis and classification of diabetes mellitus and its complications. Part 1: diagnosis and classification of diabetes mellitus. Report of a WHO consultation, Geneva, 1999. http://whqlibdoc.who.int/hq/1999/ WHO_NCD_NCS_99.2.pdf

13 Veldhuis JD \& Johnson ML. Cluster analysis: a simple, versatile and robust algorithm for endocrine pulse detection. American Journal of Physiology 1986250 E486-E493.

14 Consensus guidelines for the diagnosis and treatment of adults with growth hormone deficiency: summary statement of the Growth Hormone Research Society Workshop on Adult Growth Hormone Deficiency. Journal of Clinical Endocrinology and Metabolism 199883 379-381.

15 Benito P, Avila L, Corpas MS, Jiménez JA, Cacicedo L \& Franco FS. Sex differences in growth hormone response to growth hormonereleasing hormone. Journal of Endocrinological Investigation 1991 $14265-268$.

16 Smals AE, Pieters GF, Smals AG, Benraad TJ, Van Laarhoven J \& Kloppenborg PW. Sex differences in human growth hormone (GH) response to intravenous human pancreatic GH-releasing hormone administration in young adults. Journal of Clinical Endocrinology and Metabolism $1986 \mathbf{6 2} 336-341$.

17 Johannsson G, Bjarnason R, Bramnert M, Carlsson LM, Degerblad M, Manhem P, Rosen T, Thoren M \& Bengtsson B. The individual responsiveness to growth hormone $(\mathrm{GH})$ treatment in GH-deficient adults is dependent on the level of GH-binding protein, body mass index, age, and gender. Journal of Clinical Endocrinology and Metabolism 199681 1575-1581.

18 Burman P, Johansson A, Siegbahn A, Vessby B \& Karlsson F. Growth hormone (GH)-deficient men are more responsive to $\mathrm{GH}$ replacement therapy than women. Journal of Clinical Endocrinology and Metabolism 199782 550-555.

19 Lo J, Mulligan K, Noor M, Schwarz J, Halvorsen R, Grunfeld C \& Schambelan M. The effects of recombinant human growth hormone on body composition and glucose metabolism in HIVinfected patients with fat accumulation. Journal of Clinical Endocrinology and Metabolism 200186 3480-3487.

Received 18 February 2005

Accepted 24 May 2005 